\title{
Probing into Teaching Method Innovation of Hidden Moral Education Curricula in Colleges
}

\author{
Yuan $\mathrm{Wu}^{1}$, Yanling $\mathrm{Wu}^{2}$ \\ ${ }^{1}$ Faculty of Education, Southwest University, Chongqing, 400715, China \\ ${ }^{2}$ Wanzhou NO.2 Senior High School, Chongqing, 404100, China
}

Keywords: Higher education, Hidden moral education, Curricula teaching

\begin{abstract}
Moral education curricula in colleges, generally, consist of explicit moral education curricula and hidden moral education curricula. Only when explicit moral education harmonizes with hidden moral education, the function and effect of moral education can be truly exerted to guide college students' ideology and morality. Traditionally, most Chinese colleges emphasize explicit moral education but ignore hidden moral education, which is unfavorable to students' growth and development. Therefore, the moral education department in colleges ought to deepen the probing into hidden moral education, actively research teaching methods of hidden moral education curricula, and greatly raise the quality of moral education, to promote students' ideological and moral standards to constantly rise.
\end{abstract}

\section{Introduction}

Moral education curricula are an inextricable part of Chinese higher education, and have significant impact on the realization of the objective of talents training of colleges and the promotion of education quality. Under the current social context, colleges, in order to raise students' moral level and creatively implement the idea of moral education, must strengthen moral curricula construction, emphasize both explicit education and hidden education, and bring hidden moral education into full pay in respect of ideological guidance and morality strengthening, to promote students to develop better via high-quality moral education. Therefore, while gradually completing explicit moral education curricula, colleges must deepen the probing into the teaching method of hidden moral education curricula, change their traditional educational ideas little by little, and unconsciously influence students via hidden moral education, to promote students' ideological and moral standards to constantly rise to guarantee students' future development.

\section{Basic Connotation of Hidden Moral Education Curricula in Colleges}

Hidden curricula also are referred to as implicit curricula or unstudied curricula. To put it simply, hidden curricula are curricula hidden between explicit knowledge and practical curricula, and include systematic curricula and atmosphere curricula throughout the educational environment. Hidden curricula are relative to explicit curricula in colleges, and are different from the curricula teaching in the conventional sense. Hidden education curricula teaching essentially is a metaphorical term. Hidden moral education curricula in colleges mainly refer to some in school life that will influence the development of student's ideology and morality. These factors are hidden or unperceivable, but some times will even exert a greater influence on students' comprehensive quality than explicit curricula do[1]. In current educational practice of Chinese colleges, hidden moral education curricula are an inextricable part of moral education, and significantly influence the cultivation of students' ideology and morality. Therefore, colleges must deepen the probing into the teaching method of 
hidden moral education curricula, and take proper measures to give hidden moral education into full play, to promote students' growth and development.

\section{Features of Hidden Moral Education Curricula}

\section{Hidden Teaching Influence}

Explicit moral education curricula, such as Marxism Principle, Ideological and Moral Cultivation and Legal Basis, etc., are a kind of explicit education, and directly influence students' moral cognition; while hidden moral education curricula are hidden in campus environment, teaching practice and campus culture atmosphere, and unconsciously influence students' ideology and morality.

\section{Widespread Influence}

In moral education in colleges, hidden moral education curricula involve extensive contents, covering all fields involved in explicit moral education curricula, closely linked with students' life, having certain relationship with colleges' macro and micro educational environment, students' family education and social education environment, and unconsciously influencing students from various aspects. The practice of hidden moral education in colleges creates an atmosphere in campus environment and living environment of students where students can freely obtain ideological and moral knowledge, and promotes students to be consciously affected by moral education, favorable to students' growth.

\section{Lasting Influence}

Comparing with explicit moral education, the influence of hidden moral education on students' ideology and morality is more lasting and stable. The material carriers of hidden moral education curricula teaching include campus culture atmosphere, spiritual education and tradition, etc., and these factors remain stable and lasting [2] in a certain period. Besides, hidden moral education curricula teaching is of the nature of psychological health education to a certain extent, can guide students' personality development and help students to form proper views on life and values via unconscious impact, and finally promote students' to develop personal mentality in the process of education, which will be a lifelong influence. Thus, the influence of hidden moral education is lasting.

\section{Teaching Method Innovation of Hidden Moral Education Curricula in Colleges}

\section{Change the concept of moral education, and develop an education idea of specialized moral education}

Sole hidden moral education will not exert certain influence on students' ideology and morality, which is of certain dependence and intangibility. Thus, it is difficult to prepare specific instructional program, definite teaching plan, and concrete teaching contents, etc. for hidden moral education, and as a result, hidden moral education is usually ignored. Thus, the effect of moral education cannot be brought into full play to positively guide students. Actually, hidden moral education is more influential than explicit moral education in respect of scope, degree and duration. Therefore, more importance also should be paid to hidden moral education curricula while explicit moral education is enhanced.

Prof. Tan Chuanbao, a famous Chinese moral education expert, proposed an idea of moral education specialization, holding that not only moral education teachers, moral education instructors, and class advisers but all other teaching staff should be proficient in the knowledge and skills of moral education. To put it other way, teaching staff should be proficient in specialized knowledge and skills, educational knowledge and skills and moral education knowledge and skills. That all teaching staff learn moral education knowledge and skills, and develop a consciousness and conscientiousness 
of moral education is one of the prerequisites for bringing the effect of hidden moral education curricula into full play, and realizing teaching method innovation of hidden moral education curricula. Therefore, it is required to develop an idea of moral education specialization, and let every teacher and student realize their own tasks in moral education, be aware of the importance of hidden moral education curricula, then spontaneously implement the idea of hidden moral education, and perform hidden moral education, to truly establish a sound and harmonious moral education system and create conditions for cultivating students' ideology and morality.

\section{Stick to the people-oriented idea, and make full use of campus cultural system to perform hidden moral education}

Campus system culture of colleges, the central embodiment of all education management ideas and spirits of the school, mainly consists of objectives of campus administration, rules, standards, and norms, affects the mentality and daily performance of teachers, students and other staff to a certain extent, and is the foundation for colleges to create a favorable teaching atmosphere and conduct moral education. Campus management system, as compulsory requirements that teachers and students should observe, tends to be too rigid to be favorable to students' morality cultivation[3] for good communication with the executive is seldom made, humanistic care is usually ignored, and even intense conflicts happen between the executive and the punished. Therefore, in the process of hidden moral education curricula teaching, the executive should develop a people-oriented idea, tap various hidden moral education resources under the guidance of the aforesaid idea, conduct humanized education and persuasion rather than traditional dogmatism, and show the authority's concern about students via administration, so as to raise students' self-consciousness and self-development consciousness in respect of morality little by little, and bring hidden moral education into full play.

\section{Raise teachers' moral level to set good examples, so as to perform hidden moral education}

Positive role models in life are the best moral education resources. For example, teachers are role models for students. It is a fact that most students tend to admire and submit to their teachers of specialized courses for teachers' specialty attainment, educational attitude, behavior and value orientation rather than common course teachers, such as moral course teacher. It is an effective way to perform hidden moral education via teachers' positive influence and model actions. The influence of teachers in respect of image, lifestyle, moral cognition on students' comprehensive quality is lasting and all-around. Therefore, the significance of teachers' model action to the implementation of moral education is immeasurable.

As the development of China's socialist market economy deepens, and the influence of the internet on the public especially college students becomes increasingly prominent, the unhealthy thoughts greatly impact students and damp the effect of moral education, which is a challenge in the way to improving moral education quality. Even some teachers also failed to stick to their bottom line of professional ethics in the process of social transformation, or delivered bad moral values to students in class to mislead students. Therefore, teachers are required to improve their comprehensive quality, build a good example, perform hidden moral education via their positive influence on students in respect of ideology and behavior, and subtly help students to form proper views and values, to constantly improve ideology and morality and to lay a good foundation for future development[4].

\section{Perform hidden moral education via campus spirit culture}

Campus spirit culture is a deep embodiment of campus culture, specifically refers to spiritual and cultural achievements and corresponding system culture and ideas that gradually developed under the influence of social culture and education background and mainstream social consciousness and ideology and be adhered to and observed by all teaching staff, and is concretely expressed in school ethos, school's education tradition and the overall thinking pattern of teaching staff. Psychologically, campus spirit culture is a mental formulary and thinking method that was formed through long-time education practice by teaching staff and sustainably develops. It is the essence of campus culture of colleges, and significantly affect students' ideology and morality. Therefore, in the implementation of 
moral education, spiritual culture construction should be emphasized, an overall design for hidden moral education based on spiritual culture should be made, rational schooling philosophy and school-running objectives should be set, and scientific guidance should be given in related education activities, so as to penetrate the idea of moral education into various activities, successfully perform hidden moral education, edify students via related education activities, gradually improve students' ideology and morality, maximize the effect of moral education, guarantee students' healthy development in future, and promote moral education to become more popular, be widely accepted, and further develop.

\section{Scientifically design hidden moral education curricula, to exert an unconscious influence}

The most prominent feature of hidden moral education is intangibility. Therefore, curriculum design should stick to the feature of intangibility. It is feasible to design moral education curricula in combination with campus cultural environment, system culture and role model of teacher to enhance the effect of hidden moral education, and penetrate the idea of hidden moral education into other subjects to subtly influence students[5]. Besides, teachers, in the process of integrating hidden moral education with subject teaching, should try their best to maximize their influence via personal examples and verbal instruction to improve teaching efficiency.

\section{Make full use of the internet to perform hidden moral education}

Presently, the internet is almost an inextricable part in our life, and affect us at any time. Advanced tool as the internet is, it also inevitably will exert negative influence. The numerous information online impacts students' thoughts, disturbing the moral education in colleges to a certain extent. Therefore, in order to bring the effect of moral education into full play, colleges should properly make use of the internet to subtly influence students via online information dissemination or online education, etc. First, an online base for moral education can be founded, where some stories and social events of moral education significance can be shared to teach students to analyze specific issues, and develop scientific ideology and morality through analysis and understanding; second, online moral education activities in combination with real life can be carried out to help students to form good ideology and morality in such activities; last, the rules and regulations for network information management should be further strengthened, to create a healthy network environment for students, guarantee that students have access to safe information, and positively guide students to obtain healthy development via positive information.

\section{Conclusions}

To sum up, hidden moral education is of great significance to the cultivation of students' ideology and morality. In order to improve students' comprehensive quality, and promote students to develop in an all-around way, colleges should emphasize moral education much more than before without lowering the quality of specialty teaching, pay equal attention to both explicit moral education and hidden moral education, and make full use of moral education by tapping the advantages of hidden moral curricula, to improve students' ideological and moral level and lay a solid foundation for students for their further development in future.

\section{Acknowledgement}

A project of Chongqing art science base; Project name: Research on Compulsory Education Arrangement Adjustment in Chongqing"; Project No.: 105030-20500107

\section{References}

[1] He Bin. Analysis of Influence of Hidden Moral Education on College Students' Core Value, Higher Education Forum, 2014 (3): 11-13. 
[2] Li Ke. Analysis of Features and Functions of Hidden Moral Education in Colleges, Academic Forum, 2015, 38(5): 173-176.

[3] Yu Tianhong, Liu Lianmei. On Hidden Moral Education in Colleges, Education and Vocation, 2014(3): 58-60.

[4] Tang Yuan. Probing into Hidden Moral Education in Physical Education in Colleges, Sports Time, 2014(2): 58-59.

[5] Feng Xiaoyan. Ethics and Virtue Construction Based on the Perspective of Hidden Moral Education of Instructors in Non-governmental Colleges and Universities, Exam Weekly, 2013(51): 20-21. 